\title{
REVIEW
}

\section{Comparison of guidelines and self-management plans in asthma}

\author{
R.J. Meijer, H.A.M. Kerstjens, D.S. Postma
}

\begin{abstract}
Comparison of guidelines and self-management plans in asthma. R.J. Meijer, H.A.M. Kerstjens, D.S. Postma. (CERS Journals Ltd 1997.

ABSTRACT: Since the rise in asthma mortality and morbidity, many guidelines and self-management plans have been published. Many of these guidelines and selfmanagement plans are not, however, based on results of previous studies but on the opinion of experts.

We compared the five most frequently cited asthma guidelines concerning treatment steps and self-management plans with special regard to peak expiratory flow (PEF)-guided plans in asthma. We also compared results of published studies with asthma-management in the context of the guidelines.

Classification of asthma severity differed considerably between the guidelines. This was also true for PEF-guided patient self-management plans. Although there was agreement on the type of drug to be used, guidelines varied with respect to when to use the drug, the "best" strategy to increase the dose, and the maximum dose. The studies available on self-management do not make it possible to determine which part of the programme is most important or cost-effective. The latter is an important issue.
\end{abstract}

Eur Respir J 1997; 10: 1163-1172.
Dept of Pulmonary Diseases, University Hospital Groningen, Groningen, The Netherlands.

\author{
Dept of Pulmonology \\ Hanzeplein 1 \\ 9700 RB Groningen \\ The Netherlands \\ Keywords: Asthma \\ guidelines \\ peak expiratory flow \\ review \\ self-management \\ treatment
}

Correspondence: R.J. Meijer

University Hospital Groningen

Received: November 71996

Accepted after revision February 91997
From 1983 onwards, an increase in asthma morbidity and mortality was noted worldwide [1]. Concerns about this rise in morbidity and mortality, despite increasing knowledge of the pathophysiology of asthma and the availability of potent antiasthma medication, led to the formation of national and international expert panels, with the aim of improving asthma management by formulating asthma guidelines. In 1990, the British Thoracic Society (BTS) [2, 3] published the first guidelines on the management of asthma in adults, and these were updated in 1993 [4]. The US National Asthma Education Program (US-NAEP) followed, with 136 pages of guidelines in 1991 [5]. In 1992, the International Consensus Report (ICR) was published [6]. In 1993, a revision of the Australian "Asthma Management Plan" (AUS-AMP), containing 64 pages, was introduced, utilizing the six step plan published in the Medical Journal of Australia in 1989 [7]. At the end of 1995, the Global Initiative for Asthma (GINA) was published as a joint effort of the National Heart, Lung, and Blood Institute (NHLBI) and the World Health Organization (WHO). Their publications include the "Global Strategy for Asthma Management and Prevention" as a workshop report and as a practical guide. Moreover, a pocket guide and a patient information booklet are available. In this review, we discuss the 48 page practical guide only [8].

All guidelines include paragraphs on asthma classification, monitoring of lung function, medication plans, education, managing exacerbations, self-management plans, and special considerations. In this review, we will evaluate some aspects of these guidelines after their introduction. We have chosen to address only the above- mentioned guidelines, although many other guidelines exist, since the ones chosen were available, supported, and cited in the literature. This review is divided in two parts. In the first part, the above-mentioned guidelines are compared, with special reference to asthma severity and the ensuing treatment steps, and to the place of peak expiratory flow (PEF) meters in asthma management. In the second part, we will review published studies on the self-management aspects of the programmes in the context of the guidelines.

\section{Comparison of guidelines}

\section{Contents}

All five guidelines are based on symptoms, PEF measurements, education, and medication use. The BTS guidelines ( 24 pages) are relatively concise and focus on chronic and acute severe asthma in adults and children, with very limited guidance for self-management of asthma. The US-NAEP guidelines are extensive, with 136 pages and many figures and examples. These guidelines use flowcharts for decision-making. However, they serve more as a complete list of possibilities than as a guide with precise algorithms to individual patient management. The ICR, with 71 pages, emphasizes the "six part asthma management programme", which includes: education; lung function; trigger control; medication plans; exacerbation management; and follow-up care. It is comparable to the US-NAEP but with less guidance for self-management in children. The AUS-AMP is also 
based on a six step plan and is similar to the ICR. The GINA practical guide reads pleasantly, is concise, schematic, and orderly.

However complete, none of the guidelines is especially explicit in algorithms for treatment of individual patients. Moreover, none of the guidelines delineates which components of the management plans are most crucial, which is important, since some parts are quite time- and/or money-consuming.

\section{Classification of severity and treatment of asthma}

Classification of chronic asthma is divided into three degrees of severity (mild, moderate and severe) (USNAEP, AUS-AMP), or four (ICR, GINA) or five steps (BTS) leading to different therapeutic strategies and outcomes of therapy (table 1). An important difference is the focus only on pretreatment features when defining severity (forced expiratory volume in one second (FEV1) or PEF) in US-NAEP, ICR and AUS-NAP as opposed to the BTS and GINA, which also address the results of therapy. All five guidelines state that treatment of mild asthma (Step 1 in BTS and ICR, and Step 2 in GINA) consists of inhaled short-acting $\beta_{2}$-agonists p.r.n. The BTS, ICR and GINA specify when it is advisable to start inhaled corticosteroids (ICS), i.e. when $\beta_{2}$-agonists are used more than once a day (BTS), more than three times a week (ICR), or more than once a week (GINA, Step 2 or mild persistent); whereas, the US-NAEP has no limit for the use of $\beta_{2}$-agonists before starting ICS. The AUS-AMP advises addition of a low dose of ICS if needed, which makes the treatment algorithm unclear. GINA advises either ICS (200$500 \mu \mathrm{g} \cdot$ day $\left.^{-1}\right)$, nedocromil, cromoglycate or theophylline. GINA prescribes (Step 2) an increase of ICS to 800 $\mu \mathrm{g} \cdot \mathrm{day}^{-1}$ on an "as needed" basis, or addition of a longacting bronchodilator for controlling asthma.

There is consensus between the guidelines in Steps 2 and 3 (or moderate asthma) as far as the type of additional medication is concerned, i.e. ICS. This consensus does not, however, apply to the amount of ICS: the US-NAEP prescribes a maximum of $800 \mu \mathrm{g} \cdot \mathrm{day}^{-1}$; the ICR a maximum of $1,000 \mu \mathrm{g} \cdot \mathrm{day}^{-1}$, and it states that supervision of a specialist is required when higher dosages are to be started; the BTS and GINA allow doses up to $2,000 \mu \mathrm{g} \cdot \mathrm{day}^{-1}$ or more; and, finally, the AUSAMP increases the dose up to $1,600 \mu \mathrm{g} \cdot$ day $^{-1}$.

Further differences between the guidelines are found in Steps 4 and 5, or severe asthma: long-acting $\beta_{2}$-agonists and oral corticosteroids are recommended both by ICR and BTS; the US-NAEP prescribes $800 \mu \mathrm{g} \cdot \mathrm{day}^{-1}$ or more of ICS, and advises oral steroids when FEV1 or PEF vary by more than $50 \%$; in the AUS-AMP and GINA, oral corticosteroids are prescribed more reluctantly, only when ICS up to $2,000 \mu \mathrm{g} \cdot \mathrm{day}^{-1}$ with or without long-acting $\beta_{2}$-agonist is insufficient. A point of discussion, not addressed in the guidelines, is that all ICS and devices are treated as if they are similar in potency and lung deposition, which is doubtful [9, 10].

Although tapering-off of medication is important in view of long-term side-effects of inhaled steroids, this has not been described in detail in any of the five guidelines. Only GINA gives some assistance by suggesting stepdown of medication when control has been sustained for 3 months, and to review therapy every 3-6 months. Since this is the most recently developed guideline, it satisfies part of the needs remaining from previous guidelines. In conclusion, there is more agreement in the above-reviewed guidelines as to which type of medication to use for asthma treatment than when to use it, and what is the "best" strategy to increase the medication used and the proper maximum dose. It remains unclear how and when to taper-off medication, probably because almost no formal studies have yet been performed in this area.

\section{Use of peak flow in the guidelines}

All guidelines advocate the use of PEF measurement for patient self-management. It is unclear from all reports whether this is based on results of previous studies.

\section{Boundaries of PEF values for treatment changes}

PEF-guided asthma management varies considerably between the different guidelines. Table 2 shows how PEF-guided zones are defined in the five guidelines reviewed. For each value of PEF, a zone or episode is described, including an action plan for drug usage. Interestingly, all guidelines use different boundaries for classification of severity, although most of them are based on the same literature [11-13]. The US-NAEP is the most strict and advocates that action should be taken, i.e., use of $\beta_{2}$-agonist, when values below $90 \%$ of an individual's optimal PEF are reached. According to the US-NAEP and ICR, oral prednisone or a double dose of ICS should be taken when PEF drops to 70-50 or $80-50 \%$ of predicted or personal best (PB) PEF, respectively. In GINA, $80-60 \%$ of an individual's PB is used to double the dose of ICS, or when not using ICS to start oral corticosteroids. Different PEF boundaries are also described in the "red zone or severe episode"; varying from $50 \%$ (US-NAEP, ICR) to 60\% (GINA, BTS), while all four guidelines prescribe different therapy in this zone/episode! The AUS-AMP guidelines are confusing because no borders whatsoever are described.

\section{Measurement of PEF values}

It is unclear in the guidelines how many times PEF should be measured each day, and whether this should be done before or after inhaling a $\beta_{2}$-agonist [14]. The ICR and the AUS-AMP mention explicitly that time is not important for defining PB. Peak flow variability, which has been mentioned in classifying asthma severity (table 1) is not mentioned at all in the peak flow zone system (table 2), except by GINA. It seems reasonable not to use PEF variability for treatment decisions by patients, since calculating PEF variation by the patient at home can be difficult and may lead to additional variability in management. In our opinion, the guidelines underestimate the impact of inaccurately defining PB according to time and medication before measuring PEF, which probably has consequences for therapy. 


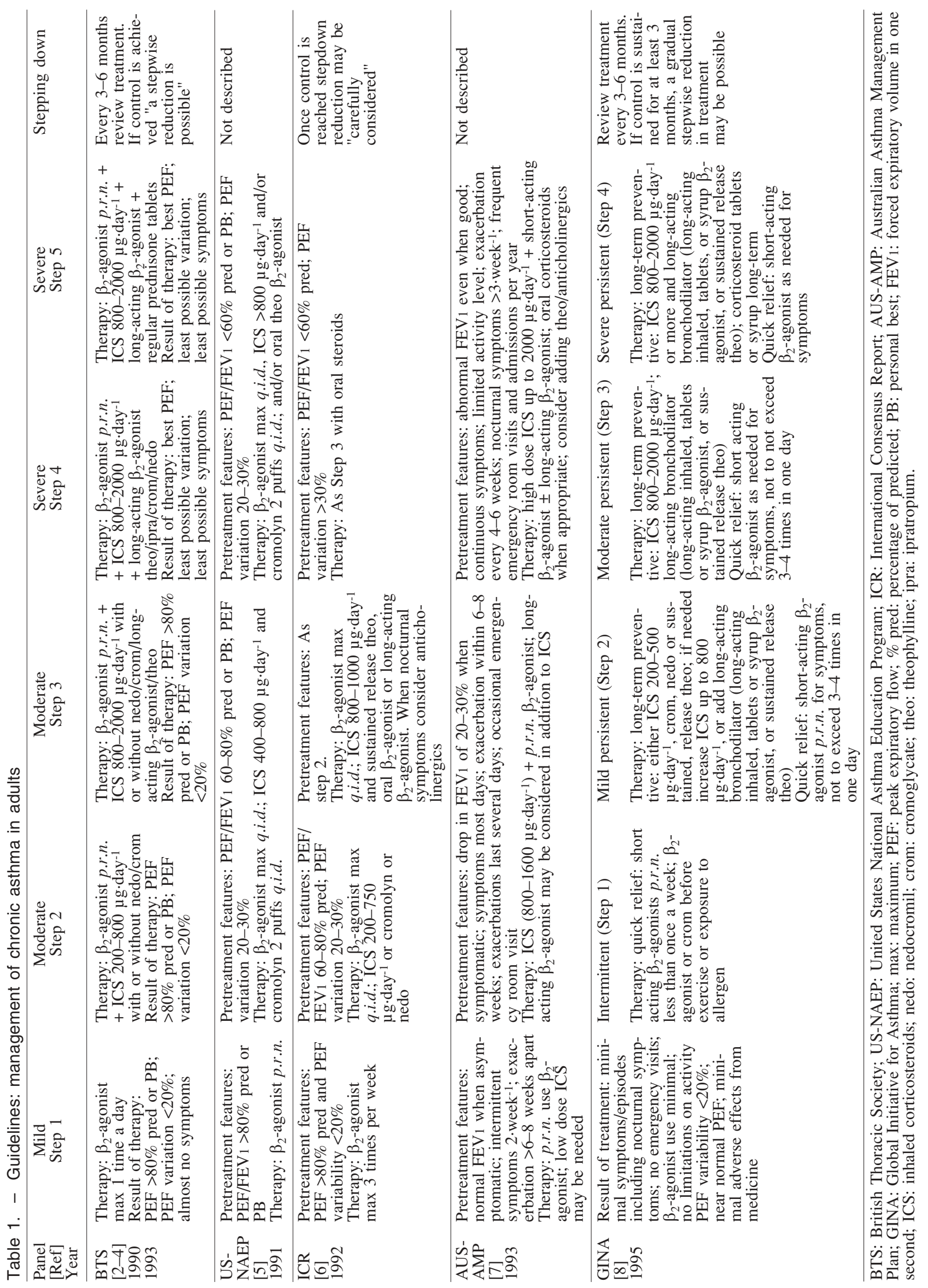


Table 2. - Guidelines: peak flow-guided zone system in patient self-management

\begin{tabular}{|c|c|c|c|c|c|c|c|c|}
\hline \multirow[t]{2}{*}{ Panel } & \multirow{2}{*}{$\begin{array}{c}\text { Characterization } \\
\text { PEF } \\
(\% \text { pred or } \mathrm{PB})\end{array}$} & \multicolumn{2}{|c|}{$\begin{array}{l}\text { Green zone or } \\
\text { mild episode }\end{array}$} & \multicolumn{2}{|c|}{$\begin{array}{l}\text { Yellow zone or } \\
\text { moderate episode }\end{array}$} & \multicolumn{2}{|c|}{$\begin{array}{l}\text { Red zone or } \\
\text { severe episode }\end{array}$} & \multirow[t]{2}{*}{$\begin{array}{l}\text { Stepdown } \\
\text { design }\end{array}$} \\
\hline & & $\%$ & action & $\%$ & action & $\%$ & action & \\
\hline BTS & ND & ND & & ND & ND & $<60$ & $\begin{array}{l}\text { Oral } \\
\text { prednisone }\end{array}$ & $\begin{array}{l}\text { At optimal } \\
\text { PB }\end{array}$ \\
\hline $\begin{array}{l}\text { US- } \\
\text { NAEP }\end{array}$ & $\begin{array}{l}\text { Whichever } \\
\text { highest }\end{array}$ & $90-70$ & $\begin{array}{l}\text { Use inhaled } \beta_{2} \text {-ago- } \\
\text { nist, if not improved } \\
\text { act as if moderate }\end{array}$ & $70-50$ & $\begin{array}{l}\text { Oral prednisone or } \\
\text { double ICS }\end{array}$ & $<50$ & $\begin{array}{l}\text { Bronchodilator } \\
\text { lator and oral } \\
\text { prednisone }\end{array}$ & $\begin{array}{l}\text { Not mentio- } \\
\text { ned }\end{array}$ \\
\hline ICR & $\begin{array}{l}\text { Whichever } \\
\text { highest }\end{array}$ & ND & & $80-50$ & $\begin{array}{l}\text { Oral prednisone } 30- \\
60 \mathrm{mg} \cdot \text { day }^{-1} \text { until re- } \\
\text { turn to green zone, } \\
\text { or double ICS for } 1 \\
\text { week until PEF or } \\
\text { symptoms improve }\end{array}$ & $<50$ & $\begin{array}{l}\text { Bronchodilator } \\
\text { and go to emer- } \\
\text { gency depart- } \\
\text { ment }\end{array}$ & $\begin{array}{l}\text { Yes, des- } \\
\text { cribed in } \\
\text { yellow zone }\end{array}$ \\
\hline $\begin{array}{l}\text { AUS- } \\
\text { AMP }\end{array}$ & ND & ND & & ND & & ND & & $\begin{array}{l}\text { Not } \\
\text { mentioned }\end{array}$ \\
\hline GINA & $\begin{array}{l}\text { PB (highest } \\
\text { measurement } \\
\text { achieved at } \\
\text { the latter part } \\
\text { of the day) }\end{array}$ & ND & & $\begin{array}{l}80-60 \\
\text { or varia- } \\
\text { bility } \\
20-30\end{array}$ & $\begin{array}{l}\text { If using ICS: double } \\
\text { for } 1-2 \text { weeks or } \\
\text { until symptoms im- } \\
\text { prove; otherwise oral } \\
\text { corticosteroids } 30-60 \\
\mathrm{mg} \cdot \mathrm{day}^{-1} \text { until PEF } \\
>80 \% \text { PB. Frequent } \\
\text { fluctuations in yell- } \\
\text { ow zone may indi- } \\
\text { cate that green zone } \\
\text { therapy needs to be } \\
\text { increased; } \beta_{2} \text {-ago- } \\
\text { nist for quick relief }\end{array}$ & $<60$ & $\begin{array}{l}\text { Take short- } \\
\text { acting } \beta_{2} \text {-ago- } \\
\text { nist. If improve- } \\
\text { ment to yellow } \\
\text { zone PEF then } \\
\text { see action for } \\
\text { yellow zone, if } \\
\text { not look in } \\
\text { "stop attacks" } \\
\text { part of the } \\
\text { guideline }\end{array}$ & $\begin{array}{l}\text { Yes, only } \\
\text { described in } \\
\text { green zone: } \\
\text { when at } \\
\text { least for } 3 \\
\text { months in } \\
\text { this zone } \\
\text { then step } \\
\text { down }\end{array}$ \\
\hline
\end{tabular}

ND: not defined. For definitions see legend to table 1.

\section{PEF expressed as personal best or as percentage pre- dicted}

Although it makes considerable difference whether PEF is expressed as PB or \% predicted, especially in asthmatics with severely decreased lung function, the guidelines have been surprisingly vague on this issue. The BTS makes no distinction between the two parameters, whereas US-NAEP and ICR take whichever is the highest. This is probably because almost no formal comparisons between PB or \% predicted are available from the literature. The BTS advises to use a short course of oral prednisone when PEF is below $80 \%$ of predicted to obtain a personal best PEF value. Use of only PB values for treatment strategies is advised in the AUSAMP and GINA.

Comparison of PEF guidance by physician and patient self-management

A confusing picture emerges when one compares PEF guidelines as addressed in the sections on "chronic asthma management" (table 1) with PEF in the "patient selfmanagement" sections (table 2) of the guidelines. To illustrate this problem, one may consider the following: what should a doctor or patient do when a PEF of $70 \%$ of predicted or $70 \%$ PB peak flow is measured? Table 1 shows that the US-NAEP and ICR prescribe ICS, $\beta_{2}$-agonists and/or cromolyn. In contrast, medication for this situation has not been defined by the BTS and GINA, which use therapy outcome and not pre- treatment features as an end-point. When looking at the peak flow-guided zone system for patient self-management (table 2), totally different advice is given in the ICR, US-NAEP and GINA. When a PEF value of $70 \%$ of $\mathrm{PB}$ or $\%$ predicted is being measured, they advise oral steroids or doubling the dose of ICS. This is a far more aggressive therapy than mentioned in table 1 .

In conclusion, there is remarkably little agreement between the five guidelines both with regard to boundaries and expression of PEF values. It is crucial to selfmanagement by peak flow measurements that the cut-off points leading to a change in medication should be more explicit and uniform. Choices should also be made concerning the use of $\mathrm{PB}$ or $\%$ predicted, the use of morning or evening PEF values or both, and the use of PEF values before or after a $\beta_{2}$-agonist [15]. Finally, more consensus is also needed for PEF-guided therapy in which pretreatment characteristics of the patients and results of therapy are well-defined, and where response to therapy leads to the next treatment step.

\section{Results of studies within asthma management plans}

Ideally, guidelines are based on results of studies performed in previous years. These studies, however, were largely absent at the time of publication of BTS, ICR and US-NAEP. This could explain at least some of the differences between the five guidelines. Many (at least 21) papers have been published in the meantime (table 3). In these studies, the number of patients varies 


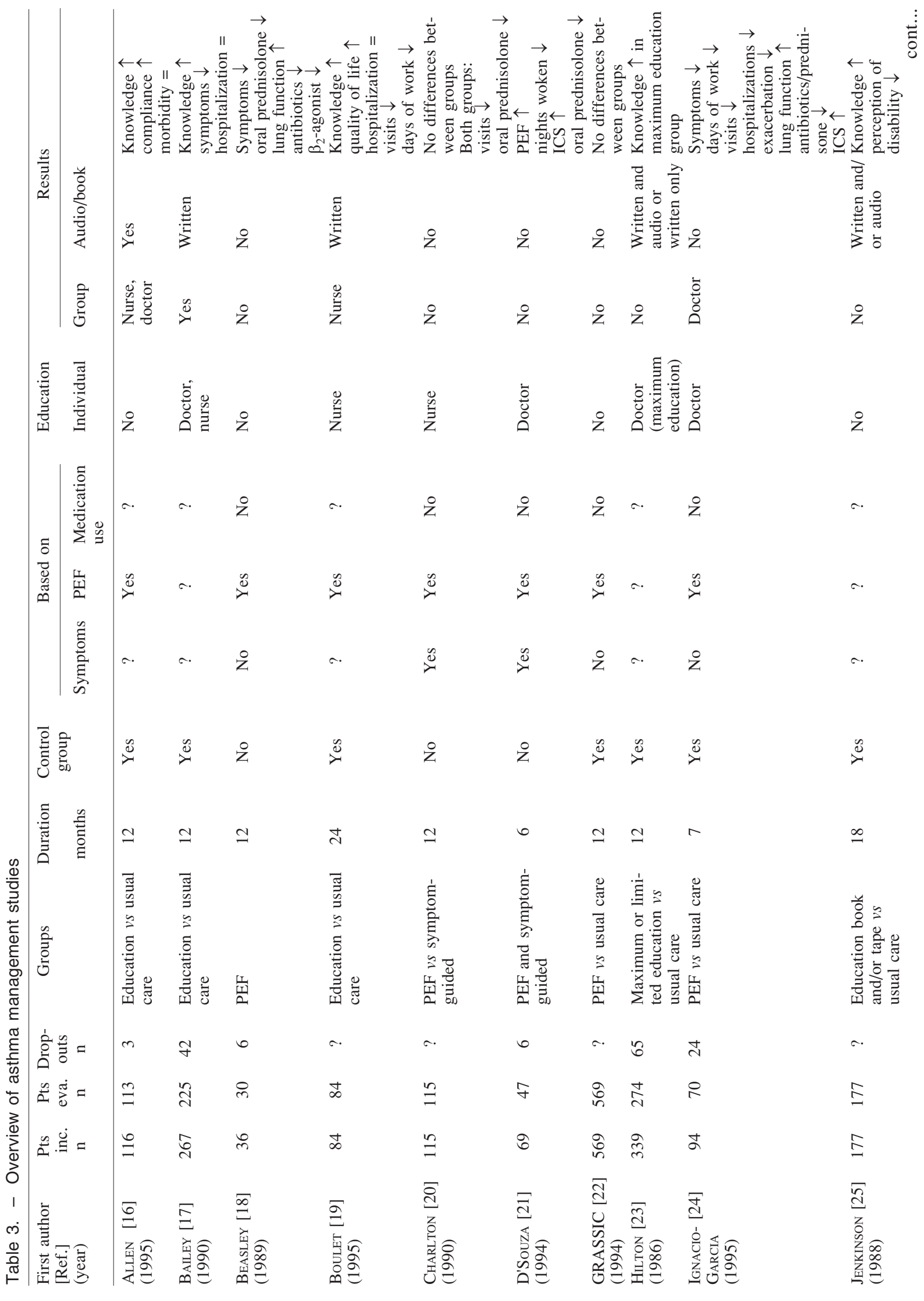




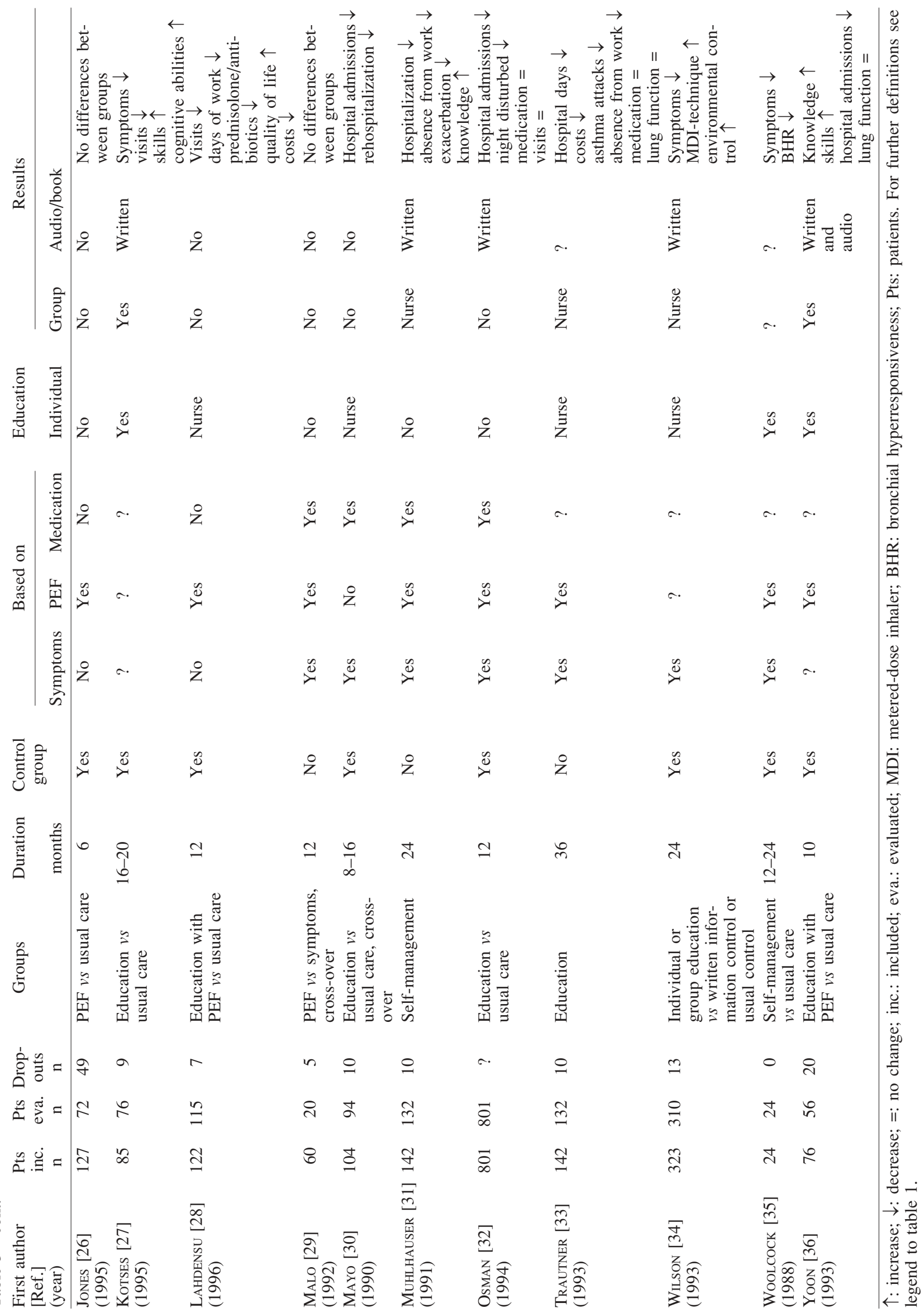


considerably from 20 to 801 , and the number of dropouts ranges from 3 out of 116 in the study by AlLEN et al. [16] to 40 out of 60 in a study by MaLo et al. [29]. The latter might suggest that self-management is not feasible for many patients with asthma.

Follow-up in these studies ranged 6-36 months, with variable intervention during this period. It is uncertain what constitutes a reasonable period for follow-up with this type of intervention, and relatively long periods might be necessary before a beneficial effect becomes apparent. It would be very interesting and important for clinical practice to see whether short-term changes, such as observed in medication use and symptoms [17, $18,21,24,27,28,33-35]$, can be maintained over several years. Although the elements of education and of PEFguided self-management plans are included in virtually all guidelines, the studies available on this topic include a different mixture of interventional aspects. This variability in design, with several simultaneous intervention elements, makes it very difficult to determine the single aspect that contributes most to the results found. It may well be that all interventions play a key role, but most studies do not prove this or even attempt to investigate it.

From the 21 studies selected, only 15 included a control group, an essential requirement for interpretation of effects of management plans. Some studies used a crossover design with fixed sequence, i.e., no intervention first and management plans afterwards.

\section{Components of asthma management programmes}

In order to try to assess the value of one single component of asthma management programmes, we have looked specifically for reports with regard to management based on education, symptoms, medication, and $\mathrm{PEF}$ in the studies available. PEF in self-management will be discussed in the next paragraph.

\section{Education programmes}

This important element has been explicitly mentioned in 15 studies. Two studies with a combination of group education and handouts of written material showed that knowledge of asthma and compliance to medication improved $[16,31]$. Two other studies investigating individual education interventions showed difference in outcome. BAILEY et al. [17] found that the knowledge of asthma increased and that symptoms improved, but the number of hospitalizations did not change. On the other hand, MAYO et al. [30] found a decrease in the number of hospital admissions, but they did not assess the knowledge of asthma. An important issue, which cannot be deduced from some study reports, is "who performed the education", i.e., a doctor, a specially trained nurse, or someone else. In seven studies, the nurse performed the education and in three the doctor. Two studies were carried out both by a doctor and nurse, and three studies did not mention the educator at all. Knowledge of asthma increased in the intervention as well as the control groups in those studies where it was measured.

\section{Symptoms}

Although symptoms have been used in 15 out of 21 studies, no study used this parameter as the sole indicator for changing therapy. Thus, it is unclear as to the value of the severity of symptoms or any combination of symptoms and objective measurements in the selfmanagement plans. Especially bothersome is the lack of any generally accepted symptom score.

\section{Medication use}

Medication usage as a parameter in management plans has been explicitly stated in 7 out of 21 studies. No study, so far, was based on need of medication use alone.

In summary, 4 out of 21 studies found no improvement in symptoms, medication use, or knowledge of asthma, and the remainder showed improvement in different outcome parameters. Because most studies comprised a mixture of interventions, such as PEF-guidance and education, it is, at present, very difficult to value separate components of asthma care. The only exception is, perhaps, the use of PEF measurements, which is described in the next paragraph.

\section{PEF-guided self-management plans}

PEF-guided self-management plans have been described in 15 publications, three of which used PEF as the single basis for a change in therapy. Two studies showed no differences between the control and intervention group [20, 22], and yet BEASLEY et al. [18] found tremendous improvements in symptoms and lung function, and a decrease of oral steroid use in the intervention group. We will compare results of studies which have based their treatment strategies largely on home PEF measurements. Emphasis will be on different boundaries used for PEF and compatibility with the guidelines.

\section{Boundaries}

Eight studies have been designed to assess the effect of self-management plans that utilize PEF zones (table 4 ). The lower limits of PEF, below which the dose of ICS has to be doubled, range $85-70 \%$ of predicted PEF or PB, in different studies. Similarly, institution of oral prednisone is advised when PEF falls below 70-50\% pred or \% PB [18, 20, 21, 24, 26, 28]. Six out of the eight studies also defined a boundary at which the patient should contact the doctor or the emergency department. This boundary ranged 25-80\% of target PEF [26, 29]. BEASLEY et al. [19] mentioned a PEF value of $150 \mathrm{~L} \cdot \mathrm{min}^{-1}$, irrespective of age, gender, height and prior PEF, as a minimum to contact the hospital or doctor.

\section{Adherence to guidelines}

Table 4 shows that three studies leave the choice to the reader to use PEF as \% pred or \% PB [18, 21, 24], while four studies postulate whether PEF is expressed 


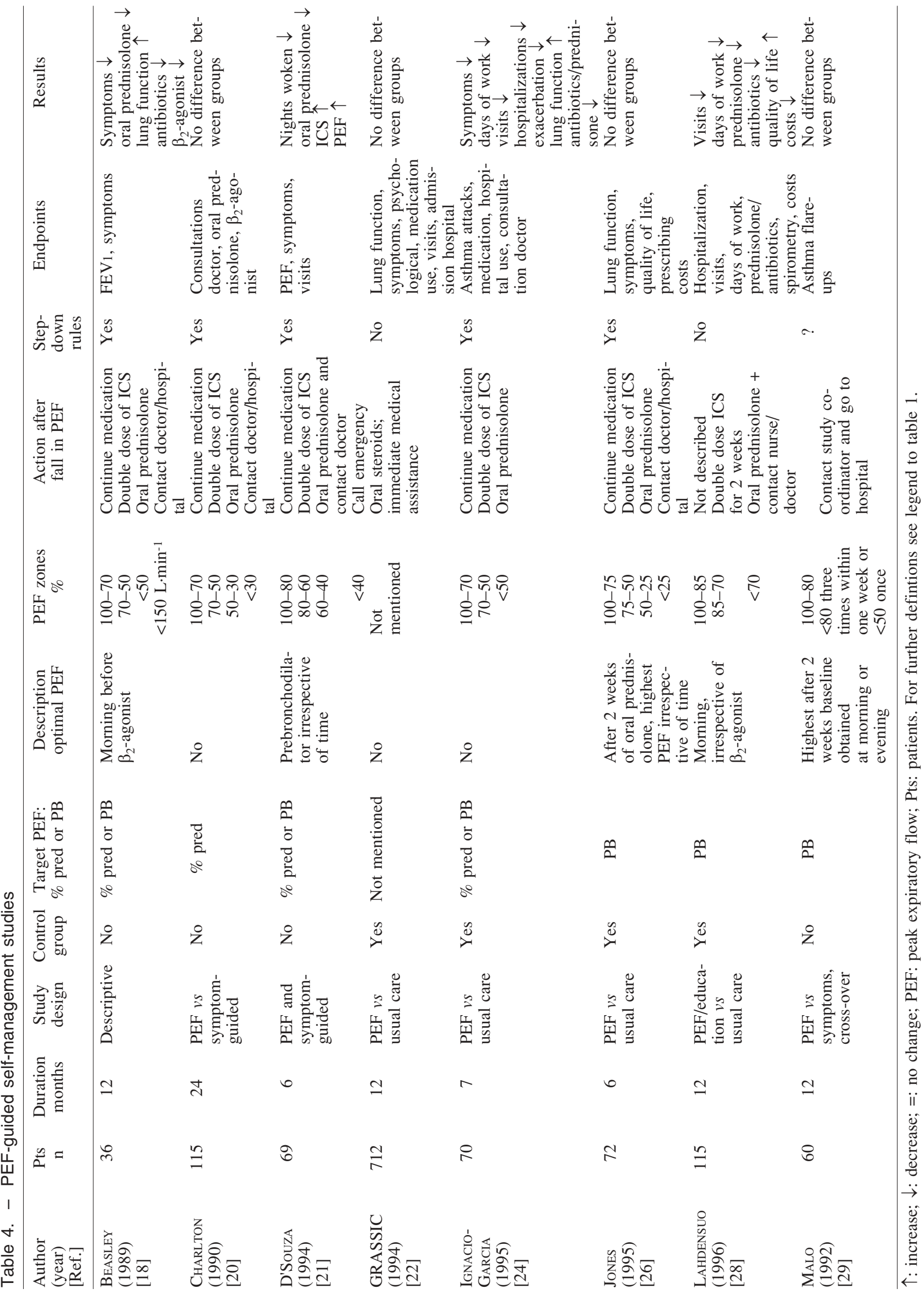


as $\%$ pred or $\%$ PB $[20,26,28,29]$. This is not in accordance with the BTS, ICR and US-NAEP guidelines, which advocate the use of either PEF expressed as \% pred or \% PB, i.e. whichever is the highest.

Formal guidelines for the use of PEF values in tapering-off of therapy have not been given. The studies available investigating the effect of self-management on asthma stability have designed their own stepdown rules. Only in the studies by Ignacio-Garcia and GonZalezSANTOS [24] and the Grampian Asthma Study of Integrated Care (GRASSIC) [22], have guidelines been specifically mentioned and adhered to. Although many of the studies reviewed were designed before the appearance of the guidelines, it is important to realize that they are not in accordance with the current guidelines.

\section{Discussion}

Views on asthma management have changed dramatically over the last decade. Following a rise in morbidity and mortality of asthma, expert groups have convened to write guidelines based on consensus of proper asthma treatment. Although consensus was based more on the opinion of experts than on sound data, since the latter were not available at that time, these guidelines have sparked the research that is necessary to give treatment algorithms the necessary scientific basis. One of the major achievements of the guidelines has been a shift away from pure medical treatment to a broader view on asthma management in general, incorporating items such as education and coping skills. An appealing part of these management programmes has been the emphasis on self-management in the home situation. Prevention of attacks and early reaction to deterioration of asthma are perhaps logical consequences of the insight of the last decade, that asthma is above all an inflammatory disease. Over 20 studies on asthma management programmes have been produced in the last $5 \mathrm{yrs}$.

As the need for a consensus on asthma treatment was felt worldwide, many expert groups have followed the BTS to produce national guidelines. When comparing the different guidelines, it is confusing to see how large are the differences between the published reports. It is difficult to discern the logical chronological sequence of newer guidelines, which are improved based on the shortcomings of the former ones. Differences between the guidelines may seem trivial, but in reality they touch the very core of the management programmes they propose. The first example of this is the fact that inhaled steroid therapy should be started early in the disease. Although appealing and theoretically plausible, the first two studies supporting this idea have only recently been published $[37,38]$. This lack of data makes it understandable why each guideline compared in this review has made so many choices, for instance a different maximal allowed number of puffs of a $\beta_{2}$-agonist after which inhaled steroids should be started (table 1). This maximum use of $\beta_{2}$-agonist ranges from once a day to once a week, which is considerably divergent. The joint WHO report (GINA) that appeared at the end of last year constitutes more of a broadly accepted and internationally supported consensus statement, with concise and realistic minutes on asthma management. Stepdown rules are urgently required to prevent prolonged usage of high dosages of ICS in many patients. However, the guidelines describe them rather vaguely. Further studies are needed to produce more objective parameters for safely stepping down the dose of ICS.

Home PEF measurements are probably the best instrument we currently have at hand, especially in those patients who do not adequately perceive a deterioration of their asthma [39, 40]. However, there has perhaps been too little appreciation of what is asked of patients who have to comply with all components of the guidelines. Patients are asked to measure PEF several times a day, which seems hardly feasible to sustain for several months, as recently shown by VERSCHELDEN et al. [41]. Proposals need to be formulated regarding the stage of the treatment at which fewer measurements are acceptable, and when to step up the measurement frequency again. Exceptions include, among others, those patients who have repeatedly been shown not to perceive attacks very well, so that these patients are urged to continue with daily measurements [42-44]. It has social consequences when one has to carry a PEF meter to every place one goes, which applies especially to young people. The latter is supported by UwYYED et al. [45], who showed that PEF measurements in young patients, even with severe asthma, do not contribute to a better management of asthma.

In conclusion, guidelines are evolving into more comprehensive programmes for doctors as well as patients. This is based increasingly on actual study results. It is unclear from the different studies which part of the selfmanagement programme is most important or cost-effective. Performing the whole range of actions described by the guidelines is money- and time-consuming, and may not be feasible for many hospitals and patients.

It is desirable to further unify the guidelines and to initiate studies which actually put the published guidelines to the test. Leading expert opinions to state of the art studies will hopefully give rise to guidelines on global control of asthma.

\section{References}

1. Pearce N, Crane J, Burgess C, Jackson R, Beasley R. Beta-agonists and asthma mortality: déjà vu. Clin Exp Allergy 1991; 21: 401-410.

2. British Thoracic Society. Guidelines for management of asthma in adults. I. Chronic persistent asthma. BMJ 1990; 301: 651-653.

3. British Thoracic Society. Guidelines for management of asthma in adults. II. Acute severe asthma. BMJ 1990; 301: 797-800.

4. British Thoracic Society. Guidelines on the management of asthma. Thorax 1993; 48 (Suppl.): S1-S24.

5. National Asthma Education Program, Expert Panel Report. In: Sheffer AL, ed. Guidelines for the Diagnosis and Management of Asthma. Bethesda, MD Publ. No. 91-3042: US Dept of Health and Human Services; 1991; pp. 1-136.

6. National Heart, Lung and Blood Institute, National Institutes of Health. International consensus report on diagnosis and treatment of asthma. Eur Respir J 1992; 5(5): 601-641. 
7. National Asthma Education Program. Asthma-management handbook. Melbourne, National Asthma Campaign Ltd. 1993; pp. 1-64.

8. National Heart Lung and Blood Institute. Global strategy for asthma management and prevention. NHLBI/ WHO workshop report. National Heart, Lung and Blood Institute, 1995; pp. 1-48.

9. Thorsson L, Edsbäcker S, Conradson TB. Lung deposition of budesonide from Turbuhaler is twice that from a pressurized metered-dose inhaler (pMDI). Eur Respir J 1994; 7: 1839-1844.

10. Barnes NC, Marone G, Di Maria GU, Visser S, Utama I, Payne SL. A comparison of fluticasone propionate, $1 \mathrm{mg}$ daily, with beclomethasone dipropionate, $2 \mathrm{mg}$ daily, in the treatment of severe asthma: International Study Group. Eur Respir J 1993; 6(6): 877-885.

11. Hargreave FE, Dolovich J, Newhouse MT. The assessment and treatment of asthma: a conference report. $J$ Allergy Clin Immunol 1990; 85(6): 1098-1111.

12. Mendoza GR, Sander N, Scherrer A. A user's guide to peak flow monitoring. Mothers of Asthmatics Inc., 1988.

13. Beasley R, D'Souza W, Te Karu H, et al. Trial of an asthma action plan in the Maori community of the Wairarapa. NZ Med J 1993; 106(961): 336-338.

14. Zureik M, Liard R, Segala C, Henry C, Korobaeff M, Neukirch F. Peak expiratory flow rate variability in population surveys. Chest 1995; 107: 418-423.

15. Gibson PG, Wldarczyk J, Hensley MJ, Murree-Allen K, Olsen LG, Saltos N. Using quality control analysis of peak expiratory flow recordings to guide therapy for asthma. Ann Intern Med 1995; 123: 488-492.

16. Allen RM, Jones MP, Oldenburg B. Randomised trial of an asthma self-management programme for adults. Thorax 1995; 50: 731-738.

17. Bailey WC, Richards JM, Brooks CM, Soong SJ, Windsor RA, Manzella BA. A randomized trial to improve self-management practices of adults with asthma. Arch Intern Med 1990; 150: 1664-1668.

18. Beasley R, Cushley M, Holgate ST. A self-management plan in the treatment of adult asthma. Thorax 1989; 44: 200-204.

19. Boulet LP, Boutin H, Cote J, Leblanc P, Laviolette M. Evaluation of an asthma self-management education program. J Asthma 1995; 32(3): 199-206.

20. Charlton I, Charlton G, Broomfield J, Mullee MA. Evaluation of peak flow and symptoms only self-management plans for control of asthma in general practice. BMJ 1990; 301: 1355-1359.

21. D'Souza W, Crane J, Burgess C, et al. Communitybased asthma care: trial of a "credit card" asthma selfmanagement plan. Eur Respir J 1994; 7: 1260-1265.

22. Grampian Asthma Study of Integrated Care (GRASSIC) Effectiveness of routine self-monitoring of peak flow in patients with asthma. BMJ 1994; 308: 564-567.

23. Hilton S, Sibbald B, Anderson HR, Freeling P. Controlled evaluation of the effects of patient education on asthma morbidity in general practice. Lancet 1986; 1(8471): 26-29.

24. Ignacio-Garcia JM, Gonzalez-Santos P. Asthma selfmanagement education program by home monitoring of peak expiratory flow. Am J Respir Crit Care Med 1995; 151: 353-359.

25. Jenkinson D, Davison J, Jones S, Hawtin P. Comparison of effects of a self-management booklet and audiocassette for patients with asthma. BMJ 1988; 297: 267-270.

26. Jones KP, Mullee MA, Middelton M, Chapman E, Holgate ST. Peak flow based asthma self-management: a randomized controlled study in general practice. Thorax 1995; 50: 851-857.

27. Kotses H, Bernstein IL, Bernstein DI, et al. A selfmanagement program for adult asthma. Part 1. Development and evaluation. J Allergy Clin Immunol 1995; 95: 529-540.

28. Lahdensuo A, Haahtela T, Herrala J, et al. Randomized comparison of guided self-management and traditional treatment of asthma over one year. BMJ 1996; 312: 748-752.

29. Malo JL, Archevêque JL, Trudeau C, d'Aquino C, Cartier A. Should we monitor peak expiratory flow rates or record symptoms with a simple diary in the management of asthma? J Allergy Clin Immunol 1992; 91(3): 702-709.

30. Mayo PH, Richman J, Harris HW. Results of a program to reduce admissions for adult asthma. Ann Intern Med 1990; 112(11): 864-871.

31. Muhlhauser I, Richter B, Kraut D, Weske G, Worth H, Berger M. Evaluation of a structural treatment and teaching programme on asthma. J Intern Med 1991; 230: 157-164.

32. Osman LM, Abdalla MI, Beattie JAG, et al. Grampian Asthma Study of Integrated Care (GRASSIC). Reducing hospital admission through computer supported education for asthma patients. BMJ 1994; 308: 568-571.

33. Trautner C, Richter B, Berger M. Cost-effectiveness of a structured treatment and teaching programme on asthma. Eur Respir J 1993; 6: 1485-1491.

34. Wilson SR, Scamagas P, German DF, et al. A controlled trial of two forms of self-management education for adults with asthma. Am J Med 1993; 94: 564-576.

35. Woolcock AJ, Yan K, Salome CM. Effect of therapy on bronchial hyperresponsiveness in the long-term management of asthma. Clin Allergy 1988; 18: 165-176.

36. Yoon R, McKenzie DK, Bauman A, Miles DA. Controlled trial evaluation of an asthma education programme for adults. Thorax 1993; 48: 1110-1116.

37. Haahtela T, Järvinen M, Kava T, et al. Effects of reducing or discontinuing inhaled budesonide in patients with mild asthma. N Engl J Med 1994; 331(11): 700-705.

38. Overbeek SE, Kerstjens HAM, Bogaard JM, Mulder PGH, Postma DS. Is delayed introduction of inhaled corticosteroids harmful in patients with obstructive airway disease? Chest 1996; 110: 35-41.

39. Taitel MS, Kotses H, Bernstein L, Bernstein DI, Creer TL. A self-management program for adult asthma. Part 2. Cost-benefit analysis. J Allergy Clin Immunol 1995; 95(3): 672-676.

40. Clark NM, Evans D, Mellins RB. Patient use of peak flow monitoring. Am Rev Respir Dis 1992; 145: 722-725.

41. Verschelden P, Cartier A, L'Archevêque J, Trudeau C, Malo JL. Compliance with and accuracy of daily selfassessment of peak expiratory flows (PEF) in asthmatic subjects over a three month period. Eur Respir $J$ 1996; 9: 880-885.

42. Rubinfeld AF, Pain MCF. Perception of asthma. Lancet 1976; i: 882-884.

43. Kendrick AH, Higgs CMB, Whitfield MJ, Laszlo G. Accuracy of perception of severity of asthma: patients treated in general practice. BMJ 1993; 307: 422-424.

44. Fishwick D, Beasley R. Use of peak flow-based selfmanagment plans by adult asthmatic patients. Eur Respir $J$ 1996; 9: 861-865.

45. Uwyyed K, Springer C, Avital A, Bar-Yishay E, Godfrey $\mathrm{S}$. Home recording of PEF in young asthmatics: does it contribute to management? Eur Respir J 1996; 9: 872-879. 